\title{
Obtenção de Hidrogênio a partir do Ácido Sulfídrico
}

\author{
Marco Aurélio Oliveira Lima \\ Instituto de Química, Universidade Federal da Bahia, Campus de Ondina, Salvador - BA - Brasil, CEP 40170-290 \\ (???@ufba.br)
}

\section{Objetivo}

Obtenção de hidrogênio, que deverá se tornar um importante combustível para gerar energia elétrica e movimentar veículos, substituindo, aos poucos, o diesel e a gasolina.

\section{Aspectos tecnológicos}

0 gás sulfídrico $\left(\mathrm{H}_{2} \mathrm{~S}\right)$ é um gás incolor, altamente tóxico, possui cheiro de ovo podre em baixas concentrações e inibe o olfato em concentrações elevadas.

s características do $\mathrm{H}_{2} \mathrm{~S}$ são: peso molecular de 34,08; peso específico de $1,189 \mathrm{~g} / \mathrm{m}^{3}$; densidade de $1,539 \mathrm{~g} / \mathrm{L}$ a $25,5^{\circ} \mathrm{C}$; pressão de vapor de $17,7 \mathrm{~atm}$ a $20^{\circ} \mathrm{C}$; temperatura de auto ignição de $260^{\circ} \mathrm{C}$; temperatura de ebulição de $-60,4^{\circ} \mathrm{C}$; limite inferior de explosividade de $4,3 \%$; limite superior de explosividade de $46 \%$; solubilidade na água de $0,672 \mathrm{~g} / 100 \mathrm{ml}$ de água; inflamável.

$\mathrm{O}_{2} \mathrm{~S}$ é conhecido como: hidro sulfúrico; hidrido sulfuroso; hidrogênio sulfatado; ácido hidro sulfúrico; cru azedo; gás de ovo podre; gás hidro sulfúrico; sulfeto de hidrogênio; stink damps.

\section{Escopo}

Foi utilizada a palavra-chave sulphi* e o código de classificação internacional C01B3 no banco de dados Espacenet, sendo encontradas 149 patentes em dezembro de 2007.

Tabela de pesquisa por palavras-chave e código de classificação internacional

\begin{tabular}{ll}
\hline Palavras-chave e código & EP \\
\hline sulphid* $^{*}$ & 22840 \\
acid* $^{*}$ & $>100000$ \\
gas* $^{*}$ & $>100000$ \\
poluent* & 76 \\
hydrogen* & $>100000$ \\
corrosiv* $^{*}$ & 20685 \\
effluent* $^{*}$ & 27385 \\
sulphid* corrosiv* $^{*}$ & 114 \\
sulphid* hydrogen* $^{*}$ & 7962 \\
sulphid* effluent* & 460 \\
sulphid* and C01B3 & 142 \\
sulphi* and C01B3 & 149 \\
\hline
\end{tabular}




\section{Resultados e Discussão}

1. Patentes por Empresa

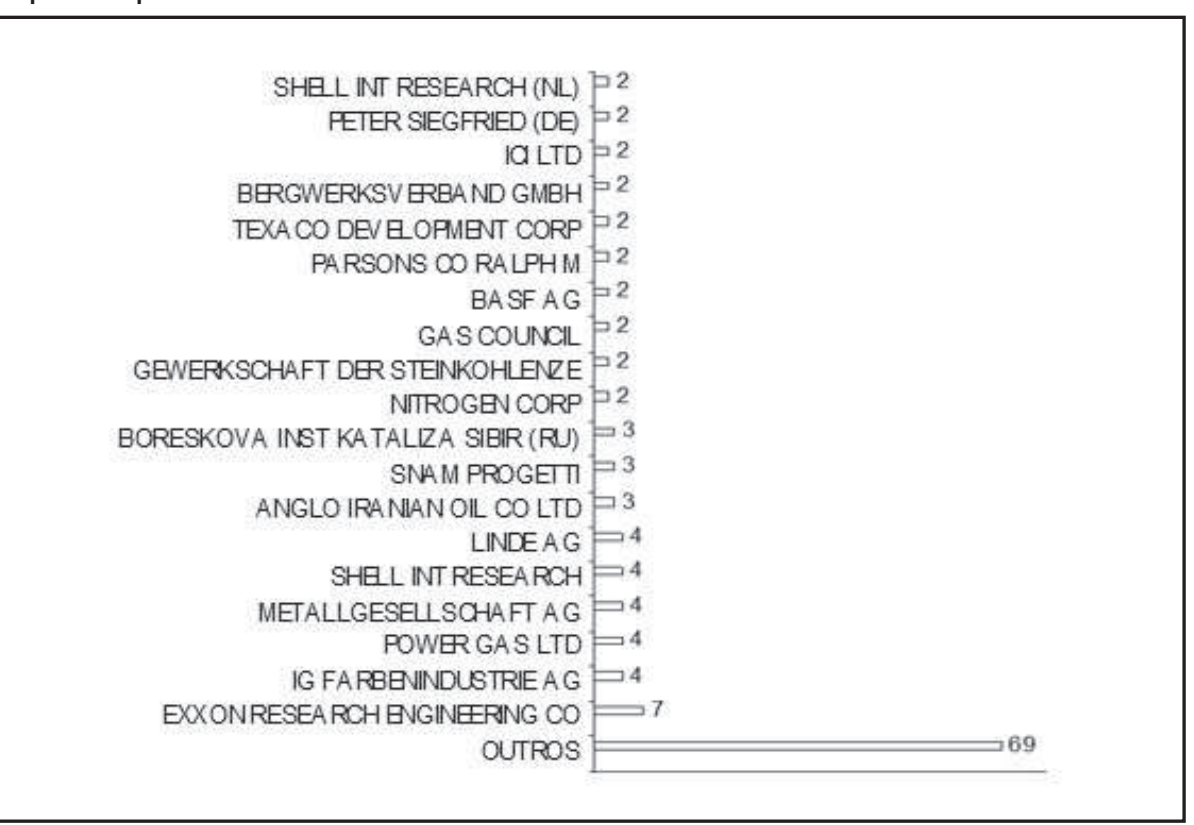

\section{Evolução Anual de Depósitos de Patentes}

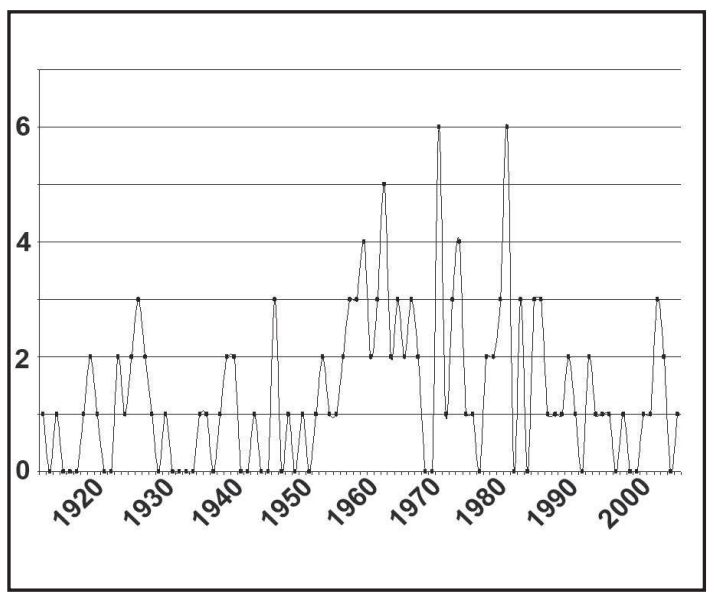

3. Patentes por País/Organização

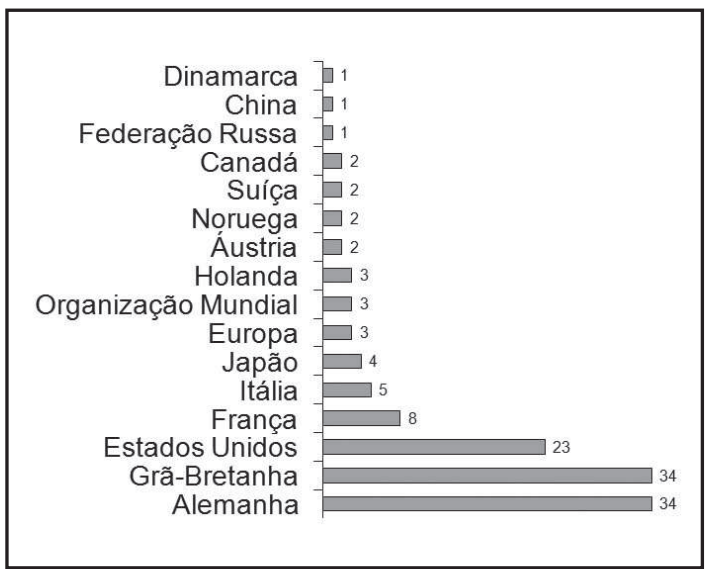

4. Distribuição por domínio mundial ou em país

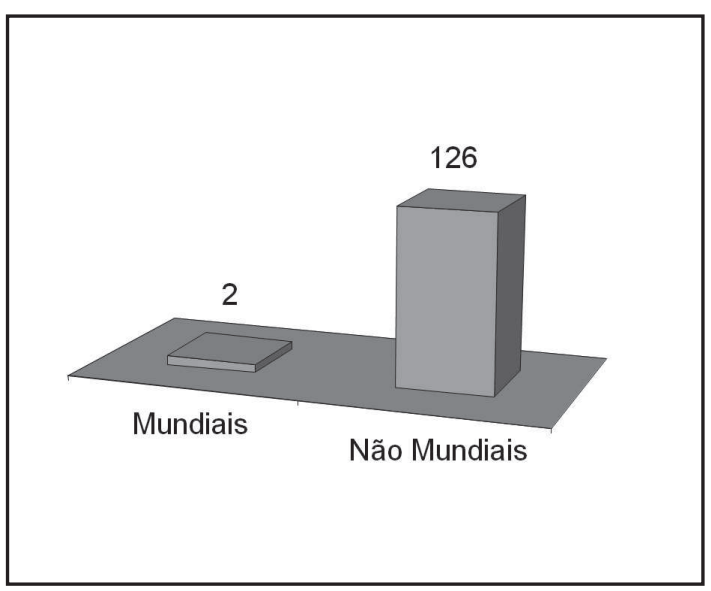

\section{Conclusões}

Países como a Alemanha, Grã-Bretanha e Estados Unidos se mostram à frente em pesquisas voltadas à obtenção de hidrogênio a partir do gás sulfídrico.

A maior produção de patentes na área de obtenção de hidrogênio e se deu entre as décadas de 60 e 80.

Marco Aurélio Oliveira Lima é aluno de graduação em Química da UFBA. Este trabalho foi realizado no semestre de 2007.2 durante a disciplina optativa "Marcas, Patentes e Propriedade Industrial" ministrada pela Prof ${ }^{a}$. Cristina M. Quintella. Não tinha tido contato anterior com o tema. 